\title{
O ENSINO DE HISTÓRIA NA PERSPECTIVA INTELECTUAL DE ALFREDO MIGUEL AGUAYO
}

\author{
Rodrigo Augusto de Souza \\ Universidade Federal do Paraná - UFPR \\ rodrigoaugustobr@yahoo.com.br
}

\section{RESUMO}

Este trabalho procura realizar um estudo sobre os fundamentos históricos, filosóficos e pedagógicos que orientam o ensino de história segundo a perspectiva do intelectual cubano Alfredo Miguel Aguayo (1866-1943). A partir da análise do seu livro "Didática da Escola Nova", publicado na coleção "Atualidades Pedagógicas" da Companhia Editora Nacional, vamos investigar o capítulo intitulado "Ensino da História". Nossa intenção é apresentar o diálogo de Aguayo com autores importantes da historiografia alemã, em especial com Bernheim, Ranke, Waitz, Sybel e Droysen. No livro de Aguayo temos também um capítulo destinado à "História Natural", o que mostra o vínculo acentuado de seu pensamento com a biologia. Pretendemos apresentar o estatuto epistemológico da história como disciplina escolar na perspectiva intelectual de Aguayo.

Palavras-chave: História da Educação; Escola Nova; Ensino de História.

\section{THE TEACHING OF HISTORY IN THE INTELLECTUAL PERSPECTIVE OF ALFREDO MIGUEL AGUAYO}

\begin{abstract}
This paper will attempt to conduct a study on the historical, philosophical and pedagogical foundations that orientated the teaching of history from the perspective of the Cuban intellectual Alfredo Miguel Aguayo (1866-1943). From the analysis of his book "Didática da Escola Nova", published in the collection of "Atualidades Pedagógicas", published in the "Companhia Editora Nacional", I will investigate the chapter entitled "Ensino de História". Our intention is to present a dialogue between Aguayo and some important German historiography authors, particularly with Bernheim, Ranke, Waitz, Sybel and Droysen. In Aguayo's book there is a chapter on "História Natural", which presents a strong connection of his thought with biology. We intend to present the epistemological status of history as school material from the intelectual perspective of Aguayo.
\end{abstract}

Keywords: History of Education; New School; Teaching of History.

\section{Introdução}

A obra do intelectual cubano Alfredo Miguel Aguayo (1866-1948) foi amplamente estudada e divulgada no Brasil no bojo do movimento de renovação das ideias e das práticas educacionais denominado de Escola Nova. Entre seus livros difundidos na educação brasileira estão: Didática da Escola Nova, com mais de 13 edições e Pedagogia Científica, que ultrapassou no número de 11 edições. O educador cubano teve suas obras traduzidas para a língua portuguesa por João Batista Damasco Penna e Antônio D’Ávila. Seus livros receberam notas e comentários de João Batista Damasco Penna, que foi também o diretor da coleção 
“Atualidades Pedagógicas" da Companhia Editora Nacional. Essa coleção foi responsável pela publicação dos livros de Aguayo no Brasil. Assim são apresentados os responsáveis pela tradução e notas dos livros de Aguayo no Brasil: "J. B. Damasco Penna, Antigo professor do Colégio Universitário anexo à Universidade de São Paulo, Da Universidade Mackenzie e do Colégio Rio Branco e Antônio D`Ávila, Assistente técnico do Serviço Nacional de Aprendizagem Industrial (Divisão de Ensino)". Nosso foco neste trabalho será o livro Didática da Escola Nova. Contudo, isso não dispensará recurso a outras obras de Aguayo, principalmente Pedagogia Científica, que teve ampla recepção entre educadores e leitores no Brasil.

O nosso trabalho situa-se no campo da história dos intelectuais, tal como é defendida por Gramsci (2009), na história intelectual como nos apresentam Rodrigues da Silva (2002) e Vieira (2008) e na história das ideias pedagógicas de Saviani (2007). Não pretendemos emitir um julgamento moral do pensamento e da obra de Aguayo. Acreditamos que essa não deve ser a posição adequada do pesquisador em história dos intelectuais e das ideias pedagógicas. A nossa intenção é entender Alfredo Miguel Aguayo como um personagem historicamente situado e ideologicamente vinculado com diferentes interlocutores que marcam e fundamentam o seu pensamento pedagógico. Buscamos compreendê-lo como intelectual e identificar as principais características do seu pensamento pedagógico. Isso significa perceber as incoerências e contradições que marcam suas ideias e sua trajetória intelectual. Segundo Miranda (2011), Aguayo foi uma "personalidade polêmica". Um simples contato com suas obras já nos mostra isso. Para um estudioso dos dias de hoje não passariam despercebidos os capítulos sobre: "Ensino de História Natural, Ensino de Higiene, Ensino de Moral, A Instrução Cívica e o Trabalho Manual”. Esses capítulos integram a obra Didática da Escola Nova, que servirá de base para a nossa pesquisa.

Apesar de nos concentrarmos na análise do compêndio de didática escrito por Aguayo, traduzido e muito divulgado no Brasil, nosso objetivo é estudar um capítulo em particular: "Ensino da História". Pretendemos investigar as perspectivas historiográficas que marcam o pensamento de Aguayo. Qual a sua compreensão de história? De que forma se dá o trabalho didático para o ensino da história como disciplina escolar segundo o pensamento de Aguayo? Quais são suas principais matrizes historiográficas? Que tipo de diálogo é estabelecido por Aguayo com outros autores que fundamentam a sua compreensão da história?

Tomaremos o cuidado de não chamar de manual o livro de Aguayo, mas de compêndio. Essa expressão foi utilizada por Damasco Penna (1958) para se referir ao livro Pedagogia Científica. Afirmou: "êste compêndio tem contribuído, entre nós, com bons serviços à obra de formação profissional de professôres, principalmente de professôres do ensino primário, a cujas necessidades de cultura particularmente se adapta". O termo compêndio parece adequar-se mais à pretensão cientificista de Aguayo. Diferente do manual, o compêndio tem a conotação mais científica e demonstra uma destinação mais para a prática profissional, principalmente entre as ciências biológicas e médicas. Para Saviani, os manuais didáticos são uma herança do pensamento católico e da tradição tomista e neo-tomista na educação: "Há diversos textos e manuais de Filosofia da Educação que seguem essa orientação" (SAVIANI, 1991, p. 25). Não entraremos nos detalhes da discussão etimológica entre os termos compêndio e manual. No entanto, segundo nosso entendimento, o compêndio está mais ligado ao pensamento humanista leigo, fundando na discussão sobre a natureza humana e com pretensões científicas à moda da biologia.

Desse modo, o nosso estudo está em sintonia com as pesquisas que tratam da análise dos compêndios, manuais, e livros didáticos, em especial, as obras dedicadas à história da educação. A ideia principal é "desmistificar" o compêndio, mostrar suas determinações históricas, suas opções ideológicas e, ao mesmo tempo, perceber como a sua análise nos permite a compreensão da educação em um dado período histórico. Para Morgado (2004), os 
manuais de ensino por muito tempo foram inquestionáveis e detentores de uma suposta verdade infalível. Não podemos negar que eles prestaram uma valiosa contribuição ao conhecimento. Com suas pretensões universais, muitos deles são excelentes sistematizações das ciências e dos saberes produzidos pelo homem ao longo da história. No entanto, é preciso também problematizá-los, investigar os seus limites e identificar suas incoerências internas. Nenhum manual didático é "neutro", isento de qualquer ideologia ou intencionalidade.

Não causa estranhamento o fato de Aguayo, que se auto-definia como seguidor do pensamento de John Dewey (1859-1952), ter se dedicado a escrever compêndios de ensino. O lugar do livro didático na pedagogia deweyana é um ponto problemático. Para Dewey, o "ensino livresco" era sinônimo da educação tradicional. Tratava-se de uma oposição: "aprender por livros e professôres e aprender por experiência" (DEWEY, 1971, p.7). Isso deu margem a inúmeras interpretações equivocadas da pedagogia de Dewey. O educador norteamericano não era contra o uso do livro didático pelo aluno, no entanto, criticava a sua supervalorização em detrimento da experiência de aprendizagem feita pelo educando. Aqui reside certa particularidade no pensamento de Aguayo frente a outros autores que teorizaram sobre a pedagogia da Escola Nova.

\section{O Intelectual Cubano}

Nascido em 28 de Março de 1866, na cidade de Ponce, em Porto Rico, o intelectual Alfredo Miguel Aguayo y Sanchéz (1866-1943), logo se mudou para Cuba, onde viveu a maior parte de sua vida. A nossa opção nesse estudo é designar Aguayo como pensador cubano, uma vez que ele viveu praticamente toda a sua vida nesse país, onde também obteve toda a sua formação profissional e desenvolveu sua atividade intelectual. Na Universidade de Havana, na capital cubana, formou-se em Direito e doutorou-se em Pedagogia. Atuou toda a sua vida como educador em várias escolas, na Universidade de Havana, onde foi diretor da "Escuela de Pedagogia"; foi autor de inúmeros textos e livros para uso nas escolas primárias, principalmente destinados aos professores. Foi presidente da "Asociación Pedagógica de La Habana" e colaborou em diversas revistas, tais como: Revista Educación, Universidad de La Habana, El Mundo, Revista Bimestre Cubana, Revista Pedagógica Cubana, entre outras. Além disso, Aguayo percorreu inúmeros países divulgando suas ideias. Alguns de seus livros foram traduzidos para outras línguas e publicados no estrangeiro (MIRANDA, 2011).

Segundo Gramsci (2006), na formação dos intelectuais na América do Sul e Central:

Inexiste uma ampla categoria de intelectuais tradicionais, mas o problema não se apresenta nos mesmos termos que nos Estados Unidos. De fato, encontramos na base do desenvolvimento desses países os quadros da civilização espanhola e portuguesa dos séculos XVI e XVII, caracterizada pela Contra-Reforma e pelo militarismo parasitário. As cristalizações ainda hoje resistentes nesses países são o clero e uma casta militar, duas categorias de intelectuais já fossilizadas na metrópole européia. [...] A maior parte dos intelectuais é do tipo rural e, já que domina o latifúndio, com extensas propriedades eclesiásticas, estes intelectuais são ligados ao clero e aos grandes proprietários. A composição nacional é muito desequilibrada mesmo entre os brancos, mas complica-se ainda mais pela imensa quantidade de índios, que em alguns países formam a maioria da população. [...] $\mathrm{O}$ elemento laico e burguês ainda não alcançou o estágio da subordinação dos interesses e da influência clerical e militarista à política laica do Estado moderno. Ocorre assim que, por oposição ao jesuitismo, tenham ainda grande influência a Maçonaria e o tipo de organização cultural como a "Igreja positivista" (p. 31). 
A atuação intelectual de Aguayo é anterior à Revolução Cubana, ocorrida em 1959. Cuba ainda não conhecia a era Fidel Castro, nem as significativas mudanças ocorridas no país a partir desse período. Acreditamos que a afirmação de Gramsci nos ajuda a compreender bem a história dos intelectuais na América do Sul, Central, e, principalmente, em Cuba. Temos no contexto histórico de Aguayo o predomínio dos intelectuais de "tipo rural", ligados aos grandes proprietários de terra. Pela formação recebida, notamos que Aguayo pertencia a esse grupo, uma vez que estavam ausentes os elementos de uma formação eclesiástica ou clerical. Outro dado importante é a formação de um pensamento burguês, como forma de contraposição ao domínio da Igreja, representado principalmente pela maçonaria e pelas ideias de tendência liberal.

No caso de Aguayo não há uma oposição radical contra a Igreja católica, como encontramos em outros intelectuais ligados ao movimento da Escola Nova. Em seu compêndio Didática da Escola Nova, quando trata da questão do "ensino de moral", Aguayo tenta encontrar posição conciliadora entre a escola leiga e a religião.

É impossível resolver, cremos que a religião de caráter sectário tem seus agentes de educação: a Igreja, a família e a escola sabática ou dominical. Em um país onde os pais de família pertencem a diversas confissões e muitas vezes não pertencem a nenhuma, o ensino de moral na escola pública não pode deixar de ser leigo. Por outro lado, a moral leiga não se divorcia necessàriamente da religião. Assim o entendem os criadores da escola leiga, como Buisson, Pécaut e Steeg, os quais sustentam que a moral deve ensinarse com espírito religioso. É assim também que se faz nas escolas norteamericanas e de outros países, onde o laicismo jamais foi interpretado como sinônimo de tendência irreligiosa nem, muito menos, de anti-religiosa (AGUAYO, 1966, p.229).

O pensamento de Aguayo apresenta alguns problemas como: a) "a moral leiga não se divorcia necessariamente da religião"; b) "deve-se ensinar moral com espírito religioso"; c) "o laicismo jamais foi interpretado como sinônimo de tendência irreligiosa nem, muito menos, de anti-religiosa". Esses pontos precisam ser esclarecidos dentro do projeto intelectual de Aguayo. Para a edição brasileira, os tradutores João Batista Damasco Penna e Antônio D`Ávila apresentaram na mesma página uma nota citando a obra do padre jesuíta Leonel Franca (1893-1948), "Ensino Religioso e Ensino Leigo" para esclarecer sobre o papel da religião na escola pública. Outros intelectuais católicos são citados: padre Álvaro de Negromonte, monsenhor José Tibúrcio, Waleska Paixão, Evangelina Gonzaga, Julieta Magalhães Lopes e Carolina Nabuco. Muitos desses autores escreveram catecismos e o "ensino religioso" era sinônimo de catecismo católico nas escolas públicas. Essa era a aparente postura "conciliadora" que Aguayo deixou entrever nas páginas de seu compêndio destinado à formação de professores.

Outra diferença em relação ao pensamento de Dewey é a preocupação do intelectual cubano com a higiene, que para o autor adquire conotações mentais e morais. Não se trata apenas do cuidado com o corpo em seu aspecto físico e biológico, mas também da formação do caráter e da moralidade, por meio da higiene mental. Não encontramos qualquer menção à higiene na pedagogia deweyana. Não há qualquer relato sobre isso nos livros do educador norte-americano, do qual Aguayo demonstrava ser partidário. É interessante notar no Brasil, mesmo no campo do pensamento católico, que o pensamento higienista esteve presente; o padre Álvaro de Negromonte dedicou-se ao tema da higiene em alguns de seus catecismos. Nesse sentido, há uma aproximação entre católicos e liberais (CURY, 1984).

Para Boarini (2003), a higiene tem por base a naturalização do social, isto é, trata em termos da biologia aquilo que é da esfera social, política e econômica. Segundo a autora, o pensamento higienista busca sua justificação intelectual na concepção de natureza humana de Jean Jacques Rousseau (1712-1778). Outro teórico muito importante é Charles Darwin (18091882) com o seu naturalismo evolucionista. Sabemos que os dois autores em questão são 
personagens importantes para o movimento da Escola Nova. Contudo, teremos diferentes leituras desses pensadores entre os intelectuais partidários do movimento. As diferenças que são de ordem sociológica são tratadas como naturais no pensamento higienista. Trata-se da transposição do modelo cientificista das ciências natureza para as ciências humanas e sociais.

No prefácio de seu compêndio Didática da Escola Nova, Aguayo afirma que seu livro se presta ao estudo de uma "nova metodologia pedagógica", oferecida ao professor. Logo de início critica os outros autores que tratam do mesmo tema por não terem uma "atitude científica", abordando apenas "experiências pessoais" e não considerando o assunto da didática de um "ponto de vista geral e sistemático". Aguayo sustenta que "contra essa confusão e falta de método reagiram muitos educadores da Alemanha e de outros países, os quais lançaram os fundamentos e construíram o edifício de uma nova didática". Já percebemos no começo da obra a relação do intelectual cubano com autores da Alemanha e também de outras nacionalidades. Esse tema da presença do pensamento alemão na obra de Aguayo retornará ao nosso estudo quando tratarmos especificamente do ensino de história e das fontes historiográficas que servem de fundamento para o encaminhamento da história como disciplina escolar (AGUAYO, 1966, p. XVII).

O intelectual reclamou uma "atitude científica" para a didática e defendeu que o "assunto" fosse tratado de um ponto de vista "geral e sistemático". Resta-nos problematizar o que Aguayo entende por atitude científica e principalmente por ciência. Em seu livro Pedagogia Científica, o autor propõe, por exemplo, o uso da estatística na educação. Citou suas experiências na aplicação de testes para "medir" o nível de aprendizagem dos alunos em Cuba. O livro também vem acompanhado de gráficos e tabelas que demonstram do ponto de vista quantitativo e estatístico o desempenho das crianças. Não encontramos esses elementos no pensamento de Dewey. Como o próprio título da obra sugere, Aguayo tem a pretensão de fazer da pedagogia uma ciência rigorosa como as ciências da natureza, daí a importância da estatística na educação. $O$ positivismo tinha essa preocupação com fato, com a quantificação do dado. Em uma passagem desse livro, o pensador investigou a "extensão do vocabulário das crianças cubanas de raça branca" (AGUAYO, 1958, p. 48). Fica nítido o vínculo do autor com o pensamento higienista. Devemos entendê-lo no seu contexto histórico, ou seja, estudar o seu pensamento em um tempo determinado, evitando apresentar questões dos dias atuais que não estavam colocadas naquela época.

Assim se pronuncia através de notas o tradutor de Pedagogia Científica sobre a aplicação da estatística na educação brasileira:

Só há pouco tempo temos nós cuidado, no Brasil, de estatística escolar. Ver. Estatística escolar 1930 (do Estado de São Paulo), publicação da Diretoria Geral de Ensino deste Estado, São Paulo, Junho de 1931, com notável introdução de Lourenço Filho, diretor do ensino na época; Teixeira de Freitas, $O$ ensino primário no Brasil, Melhoramentos, vol. XXI da "Biblioteca de Educação", São Paulo, $\mathrm{s} / \mathrm{d}$. (Neste livro vem minuciosamente examinada a situação do ensino primário em cada um dos Estados; no prefácio, Lourenço Filho historia ràpidamente $\mathrm{o}$ que tem sido a estatística escolar no país). Teixeira de Freitas, diretor-geral de Estatística do Ministério da Educação e Saúde Pública, foi, durante largos anos, o grande batalhador da estatística escolar no país; sob sua orientação foi cumprido o Convênio Estatístico estabelecido entre a União e os Estados e foram feitas excelentes publicações estatísticas (PENNA, 1958, p. 45). 
Essas caracterizações do pensamento intelectual de Aguayo ainda apontam para o seu vínculo com aquilo que Gramsci chamou de americanismo. Um trabalho interessante seria pontuar a relação de Cuba com os Estados Unidos. Sabemos que após a Revolução Cubana, muitas pessoas do país buscaram refúgio nos Estados Unidos. Cabe-nos indagar se essas relações políticas não estavam em curso já na época de Aguayo.

\section{A Pedagogia como Ciência}

No projeto intelectual de Aguayo temos a intenção do autor de transformar a pedagogia em uma ciência, ou desenvolvê-la a partir de uma "atitude científica". Essa é uma questão controvertida entre os estudiosos do assunto. Seria a pedagogia uma ciência à maneira da biologia, por exemplo? Podemos nos referir à pedagogia como ciência? O que seria uma pedagogia científica? Sobre o assunto não há consenso, temos as mais variadas ideias sobre a questão.

Afirma Saviani (2009) que na pedagogia "passa-se do psicologismo pedagógico para o sociologismo, e deste para o economicismo, etc" (p.67). No caso de Aguayo, temos a cientificidade da pedagogia pela via do psicologismo de raiz positivista. Outros autores do período que tiveram seus livros publicados no Brasil também insistiam na ideia da pedagogia como ciência.

Foi o caso de Theobaldo Miranda Santos (1904-1971), que em seu manual "Noções de História da Educação", tratava da questão. A pedagogia era entendida como "ciência espiritual" e isso nos lembra o idealismo de Hegel, ao definir o primado do espiritual, isto é, do racional sobre a realidade. Assim, a pedagogia seria o fruto da "evolução espiritual", do desenvolvimento da racionalidade. A ideia de "evolução" mostra relação com certo naturalismo, característico do autor.

Ciência do espírito, por excelência, a pedagogia só pode ser compreendida, em toda a sua amplitude e totalidade, quando relacionada com a evolução histórica. Como toda ciência espiritual, seu progresso não representa simples resultado do gênio criador de um homem ou de uma época. Constituí, ao contrário, obra contínua das sucessivas gerações, trabalho gradativo da capitalização social, enfim, fruto lentamente amadurecido da tradição (SANTOS, 1960, p. 19).

O manual de Theobaldo Miranda Santos pretendia se ocupar dos "fenômenos históricos da educação", essa compreensão da história remete a uma espécie de fenomenologia da história, que pode ser tanto uma alusão à "fenomenologia do espírito" de Hegel, quanto uma espécie de "naturalização" da história, lembrando as ideias de Hurssel. A definição que Theobaldo o oferece de pedagogia sugere mais uma aproximação da filosofia hegeliana.

A preocupação de Aguayo com a estatística mostra que ele está distante da "ciência espiritual" à moda de Hegel. Isso o aproxima muito mais do positivismo, embora Comte praticamente não seja citado nos seus compêndios didáticos. Assim se pronunciou o educador cubano sobre suas obras: "Com estas obras, que juntas à minha Higiene escolar (1929), formarão uma pequena enciclopédia de educação, espero contribuir, na medida de minhas fôrças, para apontar novas orientações à ideologia pedagógica e à prática escolar de nosso país" (AGUAYO, 1958, p. 15).

A ideologia cientificista que marcou a produção intelectual de Aguayo esteve presente no modo como educador se referiu às suas próprias obras. É comum designá-las como "tratado" ou "compêndio". Sua intenção é formar uma "pequena enciclopédia de educação". O que nos remete à tradição enciclopedista francesa, embora o autor não deixe isso claro em sua obra. 
Sobre a questão da pedagogia como ciência, voltamos a considerar que:

As conceituações multiplicam-se, o pedagógico desdobra-se em múltiplos enfoques e a esperada unificação de perspectivas desfaz-se. Há os que definem a pedagogia como a ciência da educação. Outros, porém, negam-lhe o caráter científico, considerando-a predominantemente arte de educar. Para alguns, ela é antes técnica do que arte, enquanto outros a assimilam à filosofia da educação. Há, mesmo, quem a considere também teologia da educação (SAVIANI, 2009, p. 67).

Outro problema que se levanta para o entendimento da pedagogia como ciência é a afirmação feita pelo sociólogo português Boaventura Sousa Santos (2000), de que as ciências humanas e sociais copiaram historicamente o paradigma de cientificidade das ciências físicas e naturais. Houve uma transposição do método das ciências da natureza para as ciências humanas e sociais. Por isso, o autor define que as ciências humanas necessitam de paradigmas próprios e não devem mais importar sua legitimação científica da biologia. Tal parece ser o projeto intelectual de Aguayo: garantir a cientificidade da pedagogia pelas ciências exatas e biológicas.

Mesmo que Aguayo tente basear seu pensamento sobre um fundamento psicológico, temos a dizer que essa é uma discussão que também abrange a psicologia. Há duas tendências majoritárias sobre a psicologia: aqueles que a consideram como uma ciência biológica e outros que a compreendem pelo viés das ciências humanas e pela sociologia. Trata-se de uma diferença significativa na compreensão do estatuto científico da psicologia. Encontramos o emprego dessa caracterização social da psicologia em autores como Vigotsky. A tradição da psicologia russa procura concentrar-se no aspecto sociológico.

\footnotetext{
Uma das tarefas mais essenciais e urgentes do marxismo é constituir uma psicologia verdadeiramente objetiva. No entanto, seus fundamentos não devem ser nem fisiológicos nem biológicos, mas SOCIOLÓGICOS. De fato, o marxismo encontra-se diante de uma árdua tarefa: a procura de uma abordagem objetiva, porém refinada e flexível, do psiquismo subjetivo consciente do homem, que, em geral, é analisado pelos métodos de introspecção (BAKHTIN, 2009, p. 49).
}

A respeito do uso da estatística pela ciência, o filósofo Gaston Bachelard (1884-1962) defendeu o chamado princípio da incerteza. Desenvolvendo sua reflexão epistemológica a partir das ciências natureza, especialmente da física, Bachelard afirmou a necessidade de um novo espírito científico, capaz de captar a dialética da ciência. A intenção do filósofo francês foi mostrar que a história prova que o conhecimento científico só progride através de rupturas epistemológicas. Temos assim ressaltada a importância da dialética. No caso da geografia, por exemplo, não há como prever estatisticamente os índices demográficos e populacionais. Em sua história das ciências, Bachelard mostrou que os livros muitas vezes erram ao apresentar as teorias científicas. Os números presentes nos livros das ciências exatas são passíveis de interpretação e, principalmente de contradição. A ciência avança negando o conhecimento anterior que era tido como verdadeiro e fixado para sempre por leis aparentemente imutáveis. Devemos analisar o que Aguayo, o nosso autor em questão, entendeu por ciência e qual o estatuto científico pretendido por ele para a pedagogia.

O espírito científico deve formar-se contra a Natureza, contra o que é, em nós e fora de nós, o impulso e a informação da Natureza, contra o 
arrebatamento natural, contra o fato colorido e corriqueiro. O espírito científico deve formar-se enquanto se reforma. Só pode aprender com a Natureza se purificar as substâncias naturais e puser em ordem os fenômenos baralhados. A própria psicologia tornar-se-ia científica se fosse discursiva como a física, se percebesse que, dentro - como fora - de nós, compreendemos a Natureza quando the oferecemos resistência (BACHELARD, 1999, p. 30).

Para efeito do nosso estudo, problematizar a escrita dos livros de Aguayo que se afirmam como "científicos" se torna uma condição necessária para compreender o seu projeto intelectual, principalmente no que concerne ao ensino de história. A investigação do papel da psicologia na obra do intelectual cubano é outro elemento a ser explorado. Contudo, as dimensões desse estudo ultrapassam as possibilidades do nosso trabalho. "No psicologismo empirista de Wundt e discípulos [...] todas as explicações são puramente psicológicas. Wundt não reconhece a existência de um conjunto de leis específicas, puramente sociológicas, inerentes a todo signo ideológico e não redutíveis a algumas leis psicológicas individuais" (BAKHTIN, 2009, p.76). O mesmo pode ser afirmado em relação aos livros científicos ou compêndios. No estudo que citamos anteriormente, Bachelard faz uma investigação dos livros de física e química, entre outros, para sustentar que o seu conteúdo pode conter contradições e até mesmo não ser considerado como ciência. Para a pedagogia fica o questionamento sobre o seu estatuto científico. Qual seria a cientificidade própria da pedagogia?

\section{O Compêndio de Didática}

As bases da didática moderna para Aguayo são compreendidas a partir de dois grandes pensadores: Wolfgang Ratke (1571-1635) e Johannis Amos Comenius (1592-1670). Segundo Gilberto Alves (2005), o trabalho didático na escola moderna se orientou principalmente pelo pensamento de Comenius. Por sua vez, os estudos de Hoof (2004) mostram a importância Ratke para a didática da pedagogia moderna. Para Aguayo, a didática significa "a ciência e arte do ensino". Tem uma preocupação com a definição etimológica do termo, por isso vai à definição da palavra grega como arte de ensinar.

A palavra didática significou de início, a ciência e a arte do ensino. Nesse sentido tem sido empregada desde o século XVII. Em 1629, Ratke ou Ratichius escreveu, para os príncipes Anhalt-Koethen, seus famosos Aphorismi didacti precipui (Principais aforismos didáticos), e Comenius publicou, em 1657, sua obra capital, Didactica Magna ou Grande Didática (AGUAYO, 1966, p.1).

Não deixa de ser perceptível a ausência de Jean-Jacques Rousseau (1712-1778). A pedagogia de Rousseau foi muito importante para os trabalhos de Dewey, de quem Aguayo definiu-se como seguidor nas ideias pedagógicas. O intelectual cubano procurou mostrar a diferença entre a perspectiva didática da Escola Nova e a da chamada escola tradicional ou "herbartiana", pautada na instrução educativa. A recorrência ao pensamento de Johann Friedrich Herbart (1776-1841) é constante na obra de Aguayo. Lembramos que Herbart também tinha a preocupação com uma pedagogia científica.

Em outro momento do nosso trabalho, já tivemos oportunidade de afirmar o aparente caráter contraditório, para o nosso entendimento, no fato de Aguayo ter se dedicado a escrever compêndios didáticos, voltados à formação de professores. Sendo ele um partidário da pedagogia da Escola Nova, em especial de Dewey, isso causa certa surpresa, uma vez que o lugar do livro na escola "progressiva" ou "renovada" é profundamente questionado. 
No intuito de contribuir para êsse trabalho de síntese escrevi esta modesta Didática da escola nova. Fruto de perseverantes estudos que durante muitos anos fiz na Universidade de Havana, foi composta esta obra em uma série de lições dadas, de 1931 a 1932, em minha Academia Pedagógica desta cidade. Não se trata, é claro, senão de mero ensaio. [...] O progresso, hoje muito acelerado, das ciências pedagógicas, mudará radicalmente muitas das soluções hoje aceitas como firmes e até definitivas. Como tôda ciência de valôres, a pedagogia está em transformação constante. [...] Não é pequeno o serviço prestado à didática pelos educadores da escola nova, com simplificar o tecnicismo pedagógico e evitar tôda referência a muita ninharia e a muita pedantaria da velha escolha. Procuro, neste livro, não me afastar dessa excelente inovação (AGUAYO, 1966, p. XVIII).

Algumas designações são utilizadas por Aguayo para se referir ao seu compêndio de didática: "ensaio", "guia" e "livro". Já fizemos menção ao seu intuito de constituir uma "pequena enciclopédia de educação". Aguayo ainda cita no prefácio uma carta sua escrita pelo "Dr. Georges Rouma" e que o chama de "grande pedagogista". Segundo intenção do autor do compêndio, o livro deve ser tomado como "guia, de preferência, a própria iniciativa, sua originalidade e seu impulso criador". Critica ainda a "pedagogia das cópias e imitações", que "não passam de rotinas mais ou menos disfarçadas".

Certas expressões do autor usadas para apresentar o próprio trabalho chamam a nossa atenção, tais como: "progresso acelerado das ciências pedagógicas" e a pedagogia como "ciência de valôres". A ideia de progresso pode ser referência ao positivismo de Comte. Para a filosofia positivista o progresso era o fim de todas as ciências. Outra hipótese é considerar, segundo a visão de Hegel, o progresso como forma de realização do espírito, da própria razão. O entendimento da pedagogia como "ciência de valôres" nos mostra a sua relação com a moral. No pensamento de Aguayo, a pedagogia tem uma função moral, de formar valores. Podemos dizer que Aguayo transforma a pedagogia em uma axiologia. A pedagogia assume um aspecto de ética normativa, parecida com a deontologia. Isso demonstra o seu vínculo com a área do Direito, uma vez que o educador também era advogado. Alia-se a isso o seu forte pensamento higienista. Desse modo compreendemos como pedagogia se transforma em "ciência dos valôres" no projeto intelectual de Aguayo.

Outra conjectura é apontar para a presença da filosofia de Kant na obra de Aguayo. O filósofo alemão, também muito importante no campo da ética, defendeu essa proximidade entre o conhecimento e a ética normativa. Em vários momentos, na organização do seu compêndio de didática, Aguayo recorreu a autores do pensamento alemão para justificar suas ideias.

$\mathrm{Na}$ parte de seu compêndio que trata da "instrução cívica", Aguayo mostrou mais claramente o seu vínculo com o pensamento alemão. Ele afirmou ser a nova matéria uma característica das democracias modernas, uma vez que elas introduziram essa disciplina no ambiente escolar. Citou como exemplo as experiências da França e dos Estados Unidos, na área da instrução cívica. A escola, segundo essa compreensão, se alia a um conceito de nação, ela torna-se a responsável pela formação da nação e dos cidadãos.

Lembramos das críticas de Karl Marx (1818-1883), sobre a manipulação ideológica da escola por parte do Estado. Segundo a visão de Marx, presente na Crítica ao Programa de Gotha, toda influência do Estado na escola deveria ser abolida. "Coisa completamente diferente é designar o Estado como educador do povo! Longe disto, o que deve ser feito é subtrair a escola de toda a influência por parte do governo" (MARX, s/d, p. 223). O pensador ainda fazem uma distinção entre escola pública e escola estatal. A escola pública seria controlada pelas classes populares, pertenceria de fato ao povo, e não seria usada ideologicamente pelo Estado segundo seus interesses políticos. 
O tema da instrução cívica merece um estudo particular. No entanto, temos de mostrar o seu aspecto fundamental no pensamento de Aguayo. O intelectual cubano buscou justificar a importância da "matéria", como ele mesmo denomina, recorrendo ao pensamento alemão. Como fica muito evidente na afirmação a seguir:

\begin{abstract}
A Revolução Francesa de 1789 deu impulso aos esforços para a formação do cidadão. Fichte, em seus Discursos à Nação Alemã, declara que esta parte do ensino é essencial para a educação do povo. Seguindo as pegadas do grande filósofo alemão, inúmeros pedagogistas estudaram a didática da instrução cívica e os governos começaram a encarar com interesse este importante aspecto da educação (AGUAYO, 1966, p. 240).
\end{abstract}

No projeto intelectual Aguayo, teorias filosóficas aparentemente distintas, como: o idealismo, o cientificismo e o pensamento higienista encontram uma síntese. $\mathrm{O}$ autor fez como que uma conciliação entre filosofias divergentes na escrita de seu compêndio de didática. Muito esclarecedora é a nota dos tradutores, sobretudo a respeito da instrução cívica. "Como exemplo da cooperação da criança na vida social, lembraríamos várias instituições, hoje mais ou menos difundidas nas escolas, como o escotismo, os pelotões da saúde, etc. Leia-se, a respeito desses pelotões, o folheto Pelotão de saúde, da Diretoria de Instrução Pública, Sétimo distrito escolar, Rio, 1933" (PENNA \& D’ÀVILA, 1966, p. 241). Os educadores brasileiros tentaram mostrar como aconteceu a sua efetivação em disciplina em nossa escola. Essa ideia de "pelotões da saúde" nos mostra um aspecto militar, como sugere a palavra pelotão e caracteriza fortemente o ensino de higiene na pedagogia de Aguayo.

Do ponto de vista da materialidade, fenomenologia e escrita, o compêndio de Aguayo apresenta trezentas e setenta e cinco páginas, divididas em trinta capítulos. O livro ainda é acrescido de um prefácio, do próprio autor. Os capítulos vão do "Conceito e Divisão da Didática" até o "Trabalho Manual". As "matérias" de "Aritmética" e de "Linguagem", receberam dois capítulos cada. A preocupação de Aguayo é sempre com o "ensino". Existe uma atenção privilegiada para a: "Ortografia, a Escrita e a Leitura". O autor também não se esqueceu do "Ensino de Desenho e do Método do Jôgo". Há uma marca psicológica na organização dos capítulos e sua aplicação na aprendizagem da criança. Chama a atenção o capítulo vinte e seis que trata da Física, Química e Mineralogia. Por que essa preocupação de Aguayo com Mineralogia? Outras características, já mencionadas, tratam do vínculo acentuado do pensamento de Aguayo com a biologia, presentes nos capítulos sobre: Higiene, História Natural, Moral e Instrução Cívica.

\title{
O Ensino de História
}

A organização do capítulo que trata do ensino de história parte do "conceito e conteúdo da história" e termina no "preparo do professor de história". Alguns temas merecem ser destacados nesse capítulo: "a seleção dos fatos" e a "base psicológica do ensino de história". Aguayo oferece grande importância aos "fatos" históricos. Isso demonstra certa proximidade com a concepção positivista de história. Para o positivismo todo intelecto humano deveria estar subordinado aos fatos. Essa parece ser a ideia defendida por Aguayo quanto ao ensino de história.

O conceito de história para Aguayo é "o conhecimento e a narração dos fatos passados, seja qual fôr a natureza dêles". Para o intelectual cubano se entende a história pelo "estudo e a narração dos fatos humanos; ou, mais exatamente, a história narra os feitos dos homens considerados como sêres sociais". A história é compreendida como uma "cadeia de acontecimentos" que explicam "os motivos que os determinam e as conseqüências que dele 
derivam”. De início, Aguayo recorreu ao historiógrafo alemão Ernst Bernheim (1850-1942) para dizer que existem três maneiras de escrever a história: "a narrativa, a pragmática e a genética". O autor defendeu que a narrativa foi o gênero mais utilizado para escrever a história. Definiu como "concepção meramente literária da história". Com essa visão, "fica sacrificada quase sempre a verdade ao interesse estético ou ao sentimento patriótico". Essa divisão da história lembra aquela adotada por Hegel (2008), quando apresentou a história original, a história refletida e a história filosófica. Temos, portanto, um vínculo acentuado de Aguayo com o pensamento historiográfico alemão (AGUAYO, 1966, p. 211).

Destacamos a ideia de Aguayo de que a história é o "conhecimento e a narração dos fatos passados". Isso remete a uma noção de história bastante criticada atualmente. Sabemos que a história se ocupa dos homens situados no tempo e no espaço. Outro aspecto é considerar os "fatos" históricos, como se houvesse uma verdade independente da interpretação humana. Aguayo ainda acentuou o problema da narrativa na história.

Apesar de contemplar a dimensão da narrativa histórica, Aguayo não deixou de criticar os historiadores antigos como: Heródoto e Tucídides. "Até meados do século XVIII, a história conservou o caráter narrativo que lhe deu Heródoto ou a tendência pragmática representada por Tucídides e Tácito. Depois tomou a forma de um estudo genético". (AGUAYO, 1966, p. 212).

Aguayo defendeu a ideia da história como ciência. No entanto, para que ela alcançasse esse patamar precisou passar por uma "reforma da narração histórica" e uma na transformação no seu "conteúdo". O autor cubano defendeu o modelo de história proposto por Rafael Altamira (1866-1951). Esse modelo compreendia que a história deveria levar em conta todos os "fatos" e que a caracterização de um povo ou de uma guerra, seria tão importante quanto uma "escola de filosofia". Assim os tradutores apresentaram Rafael Altamira: "Notável historiador espanhol contemporâneo, autor, entre outros, de um livro recomendável neste passo: Filosofia de la história y teoria de la civilización, La Lectura, Madrid, s/d" (PENNA \& D’ÀVILA, 1966, p. 213).

A mudança no estatuto epistemológico da história, de acordo com Aguayo, veio representada por autores que conferiram um novo entendimento da narrativa e do conhecimento histórico. Os historiadores da antiguidade clássica aparecem sob uma perspectiva crítica, como já tivemos a oportunidade de expor. Para Aguayo, os historiadores da antiguidade privilegiavam o elemento histórico em detrimento da "verdade". Desse modo se expressa o intelectual sobre essa renovação no campo da história:

Mudou, de modo radical, o método empregado na investigação histórica. Antigamente escreviam os historiadores sem exame prévio da autenticidade, exatidão e interpretação das fontes que empregavam. Os trabalhos de Niebuhr, Ranke, Waitz, Sybel, Droysen, Langlois e Seignobos, Bernheim e outros lançaram as bases de um método crítico, que aspira fixar a significação do fato histórico, livre das alterações de que foi objeto ao longo da tradição. [...] Se a história é ciência, deve êsse caráter sobretudo à severidade de seus métodos de investigação e crítica. Depois de terminada a primeira guerra européia, a tendência predominante, no ensino de história, é reduzir a parte dedicada às guerras e aos chefes de nação, ampliando, em compensação, a história da cultura e da política interna (AGUAYO, 1966, p. 213).

$\mathrm{Na}$ organização da história como disciplina escolar, Aguayo citou o estudo de John Dewey, "O objetivo da história no ensino primário", para argumentar que o conhecimento histórico não pode se resumir a um estudo do passado. "Estudamos o passado para compreender melhor o presente, para saber como se formam as fôrças espirituais que atuam

Revista HISTEDBR On-line, Campinas, n.43, p. 118-131, set2011 - ISSN: 1676-2584 128 
em cada sociedade. Não é objetivo desta disciplina desenvolver o patriotismo e nem edificar a criança com altos e nobres exemplos de conduta". Para Aguayo, da história advêm "ensinamentos morais e o patriotismo", sem, contudo, serem esses os objetivos principais da disciplina escolar. Citando Rafael Altamira, afirmou que a história serve para "despertar e sugerir sentimentos essencialmente políticos ou de raça e para manter o espírito tradicional... e a penetração da própria consciência dos antepassados" (AGUAYO, 1966, p. 214).

O ensino de história como disciplina escolar é uma herança da historiografia alemã, na compreensão de Aguayo. Os "educadores" do Renascimento foram os principais defensores da disciplina. Entre eles, se destacam: Jacob Wimpfeling com o seu "Epitoma rerum germanicarum usque ad nostra tempora" e Miguel Neander, reitor da escola latina de Ifeld, que nela introduziu o ensino de história. Segundo Comenius, na Didática Magna, no capítulo vinte e nove, temos alto valor educativo na matéria de história e por isso recomendou sua inclusão na escola nacional. "Até meados do século XVIII, o ensino de história não aparece nos programas da escola elementar". Em 1763, a atuação de Frederico II introduziu o ensino de história na Prússia, ao menos nominalmente. As escolas protestantes não participaram desse processo. Aguayo prosseguiu em seu estudo sobre a origem do ensino de história na Alemanha, destacando a atuação de Herbart e Ziller. Isso evidencia a atenção privilegiada oferecida pelo intelectual ao pensamento pedagógico e historiográfico alemão. A obra de Marx, por exemplo, não aparece em qualquer momento. Nem mesmo Hegel é citado no que concerne ao ensino de história. Nietzsche, porém, é citado. (AGUAYO, 1966, p. 215).

Outros historiadores da educação, ligados ao movimento da Escola Nova, como Lorenzo Luzuriaga, por exemplo, também apresentam esse vínculo com a historiografia alemã. Para a compreensão da "realidade educacional - a ideal e a real - é necessário não só o conhecimento da Pedagogia, mas também da história". Para Luzuriaga, Wilhelm Dilthey é o "grande mestre" da história e quem lhe conferiu "valor humano" (LUZURIAGA, 1967, p. XVII).

Para Aguayo, o professor de história não necessita de "grande erudição". Segundo seu entendimento, o essencial é "um professor animador e bem preparado para o trabalho". Essas são as características do professor de história: "um juízo sadio e imparcial e patriotismo". Destacou a importância dos livros, do cinema e dos jornais, assim como do desenho e da música para ensinar história (AGUAYO, 1966, p. 225).

\section{Considerações Finais}

Procuramos com esse trabalho, realizar uma caracterização do ensino história segundo a perspectiva do intelectual cubano Alfredo Miguel Aguayo y Sanchéz. Para isso, recorremos principalmente aos seus principais livros publicados no Brasil: Didática da Escola Nova e Pedagogia Científica. Ambos atingiram inúmeras edições e integraram a coleção "Atualidades Pedagógicas", da Companhia Editora Nacional. Aguayo postulava para a pedagogia o estatuto de ciência, à maneira das ciências biológicas. Procurou conferir a ela rigor "científico", através do uso da estatística, da psicologia e da biologia, entre outras ciências. A crítica que podemos fazer a Aguayo é o fato de tratar, em termos biológicos e "naturais", aquilo que é do âmbito social e político. Em outras palavras, defender a "naturalização do social". A ideia da pedagogia como ciência provoca, ainda hoje, inúmeros debates e discussões. Mesmo que a consideremos como ciência é um equívoco tratá-la nos mesmos termos das ciências biológicas.

Outra característica marcante do pensamento de Aguayo é a "higiene física e mental". Entendia que o professor de história, por exemplo, deveria ter "juízo sadio". Justificava pela estatística o índice superior de leitura das "crianças cubanas de raça branca". Mostrou-se como uma personalidade polêmica. Defendeu o "patriotismo" entre os professores de história. 
Para a sua perspectiva intelectual, a história tinha uma finalidade moral como disciplina escolar, formar valores "cívicos e patrióticos" nas crianças e o "respeito pelos antepassados". A pedagogia era uma ciência axiológica, na sua compreensão, isto é, tinha a intenção clara de formar valores morais. $\mathrm{O}$ patriotismo, como sabemos, representa a síntese de um pensamento conservador. O discurso "patriótico" tradicionalmente pertence aos partidos políticos de direita e às forças militares.

A perspectiva intelectual de Aguayo oscila entre o positivismo cientificista e autores do idealismo alemão. Aliado a isso, existe seu vínculo e sua leitura da Pedagogia de John Dewey. Podemos afirmar que Aguayo se situa entre os partidários da Escola Nova que adotaram uma postura conservadora, mais cientificista e menos política. Suas obras publicadas no Brasil deixam transparecer o forte teor conservador de suas ideias.

\section{Referências}

AGUAYO, Alfredo Miguel. A Didática da Escola Nova. São Paulo: Companhia Editora Nacional, $13^{\text {a }}$. ed., 1966.

AGUAYO, Alfredo Miguel. Pedagogia Científica. São Paulo: Companhia Editora Nacional, $8^{\text {a }}$. ed., 1958.

ALVES, Gilberto Luiz. O Trabalho Didático na Escola Moderna. Campinas: Autores Associados, 2005.

BACHELARD, Gaston. A Formação do Espírito Científico. Rio de Janeiro: Contraponto, 1999.

BAKHTIN, Mikhail. Marxismo e Filosofia da Linguagem. São Paulo: Hucitec, 13 a . ed., 2009.

BOARINI, Maria Lúcia (org.). Higiene e Raça como Projetos. Maringá: Eduem, 2003.

CURY, Carlos Roberto Jamil. Ideologia e Educação Brasileira: Católicos e Liberais. São Paulo: Cortez; Campinas: Autores Associados, 1984.

DEWEY, John. Experiência e Educação. São Paulo: Companhia Editora Nacional, 1971.

DILTHEY, Wilhelm. Teoria das Concepções de Mundo. Lisboa: Edições 70, s./d.

GRAMSCI, Antonio. Cadernos do Cárcere. Rio de Janeiro: Civilização Brasileira, 2006, v.2.

HEGEL, Georg Wilhelm Friedrich. Filosofia da História. Brasília: Editora UNB, 2a . ed., 2008.

HOFF, Sandino. Fundamentos Filosóficos dos Livros Didáticos elaborados por Ratke, no século XVII. Revista Brasileira de Educação. Campinas: Autores Associados, jan/fev/mar/abr., 2004, p. 143-155.

LUZURIAGA, Lorenzo. História da Educação e da Pedagogia. São Paulo: Companhia Editora Nacional, 1967. 
MARX, Karl. Crítica ao Programa de Gotha. In: ENGELS, Friedrich. Obras Escolhidas. Volume 2. São Paulo: Alfa-Omega, s./d. p.203-234.

MENDES, Durmeval Trigueiro (coord.). Filosofia da Educação Brasileira. Rio de Janeiro: Civilização Brasileira, 1991.

MIRANDA, Olga Lidia. Pensamiento Pedagógico Cubano. Disponível em: $<$ http://www.cujae.edu.cu/Archivos/publicacion\%20referencia\%20pedagogia/No3/seccion7.ht m> Acesso: 29/04/2011.

MORGADO, José Carlos. Manuais Escolares: Contributo para uma Análise. Porto: Porto Editora, 2004.

SILVA, Helenice Rodrigues da. Fragmentos da História Intelectual: Entre questionamentos e perspectivas. Campinas: Papirus, 2002.

SANTOS, Theobaldo Miranda. Noções de História da Educação. São Paulo: Companhia Editora Nacional, $9^{\text {a }}$.ed., 1960.

SAVIANI, Dermeval. Educação: Do Senso Comum à Consciência Filosófica. Campinas: Autores Associados, 18 a . ed., 2009.

SAVIANI, Dermeval. História das Idéias Pedagógicas no Brasil. Campinas: Autores Associados, 2007.

SAVIANI, Dermeval. Tendências e Correntes da Educação Brasileira. In: MENDES, Durmeval Trigueiro (coord.). Filosofia da Educação Brasileira. Rio de Janeiro: Civilização Brasileira, 1991.

SOUSA SANTOS, Boaventura. Crítica da Razão Indolente. São Paulo: Cortez, 2000.

VIEIRA, Carlos Eduardo. Intelligentsia e Intelectuais: Sentidos, Conceitos e Possibilidades para a História Intelectual. Revista Brasileira de História da Educação 16, Campinas: Autores Associados, 2008, p. 63-85. 